\title{
November 11 Highlights
}

\section{A prion protein gene variant allele}

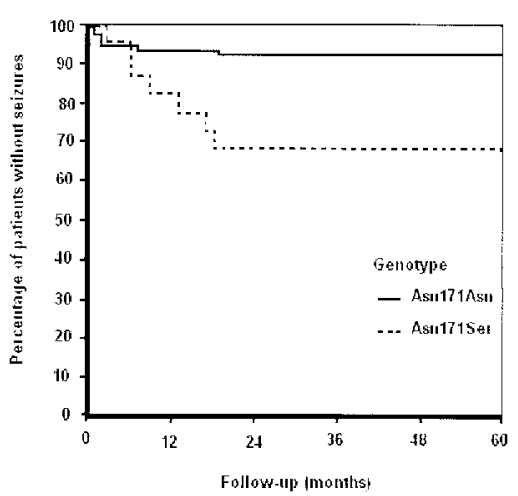

Cumulative percentages of patients who were free of seizures according to the genotype at codon 171.

In a study of 100 consecutive patients with surgically treated mesial temporal lobe epilepsy related to hippocampal sclerosis, Walz et al. found that $23 \%$ of patients (vs $0 / 180$ control subjects) had a variant allele of the cellular prion protein gene. Patients with this variant allele had a fivefold greater chance of remaining intractable after surgery.

see page 1204

The accompanying editorial by Mastrianni and Roos reviews the contribution of misfolding of the prion protein $\operatorname{PrP}^{C}$ to a protease-resistant conformation $\left(\mathrm{PrP}^{\mathrm{Sc}}\right)$, which is the infectious protein at the heart of prion diseases such as Creutzfeldt-Jakob disease (CJD) and kuru. They note that PrP knockout mice are resistant to prion disease, and although these mice have normal development and viability, they have neurophysiologic abnormalities. It is this potential role of $\operatorname{PrP}^{C}$ in neuronal excitability that led Walz et al. to investigate the association of PRNP variant alleles with mesial temporal lobe epilepsy related to hippocampal sclerosis (MTLE-HS). Mastrianni and Roos review the potential pitfalls in this type of association study but conclude that the association that Walz et al. describe may further our understanding of MTLE-HS and the importance of PrP in normal brain function.

see page 1168

\section{Optimal plasma level of topiramate in patients with epilepsy}

Studying the relationship between the plasma concentration of topiramate and effect, Christensen et al. found that concentrations in the range of 6 to 31 mmo1/L ( 2 to $10.5 \mathrm{mg} / \mathrm{L}$ ) were associated with the best outcome for patients with refractory partial epilepsy.

\section{Levetiracetam and behavioral abnormalities}

White et al. evaluated behavioral abnormalities severe enough to require discontinuation of levetiracetam. Thirty-eight patients (6.9\%; total study population $\mathrm{n}=$ 553) discontinued levetiracetam because of behavioral reasons. Variables associated with levetiracetam discontinuation included history of psychiatric disorder, faster titration rate, and symptomatic generalized epilepsy.

see page 1218

\section{Cytokine profile in SIDS brain: A common denominator in a multifactorial syndrome?}

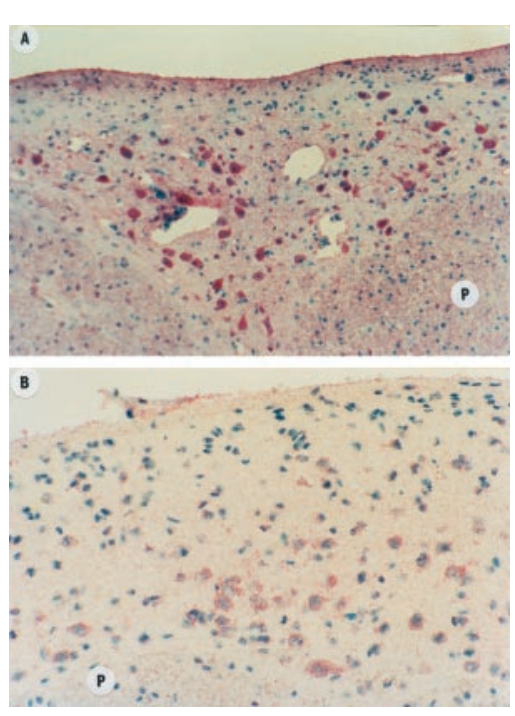

Comparison of neuronal immune staining in SIDS vs non-SIDS.
Kadhim et al. detected interleukin (IL) $-1 \beta$ overexpression in sudden infant death syndrome (SIDS) brainstem neurovegetative centers. This may tip a delicate molecular balance, causing disturbed homeostatic control of cardiorespiratory and arousal responses, possibly leading to SIDS.

see page 1256

The accompanying editorial by Bradley $T$. Thach emphasizes a potential weakness of this and many other SIDS studies: obtaining appropriate control subjects matched for age and postmortem delay. Thatch reviews the "triple risk model" of SIDS: 1) a congenital or acquired underlying vulnerability; 2) a maturational process creating a peak age of vulnerability; and 3) a precipitating immediate stress that causes sudden death, generally assumed to be cardiovascular or respiratory in origin. In this model, abnormal cytokines, possibly occurring during an upper airway infection, could be the immediate stress. 


\section{Alteration of perception of the haptic, postural, and visual vertical}

Bronstein et al. assessed two patients with vestibular brainstem lesions who had a striking tilt in the visual perception of verticality but spared perception of verticality with touch. The vestibular nuclei do not seem to encode a single internal representation of verticality.

see page 1260

The accompanying editorial by James $A$. Sharpe reviews the seldom-evaluated ability of subjects to perceive the vertical using vision, haptic, and postural assessment. In the Bronstein et al. report, by having patients adjust a visible luminous line in complete darkness to what they consider to be the upright, earth-vertical position, the subjective visual vertical was assessed. The nonvisual sense of the vertical in these patients was assessed by the manipulation of a rod to the earth-vertical position with both hands while their eyes were closed-the "haptic" vertical (HV). Haptic is a term derived from the Greek verb haptein, to fasten, meaning, "of, or relating to, the sense of touch or tactile sensations." Haptic perception involves active manipulation of objects and depends on somatosensory inflow information, efferent signals, and cognition.

see page 1172

\section{The prevalence of migraine in neurologists}

In a nationwide survey, Evans et al. found a lifetime prevalence of migraine of $46.6 \%$ in male neurologists and $62.8 \%$ in female neurologists-much greater than in the general population.

see page 1271

\section{Dietary antioxidants and the risk} of ischemic stroke

Vokó et al. studied the relation between dietary intake of antioxidants and the risk of stroke. High dietary intake of vitamin $\mathrm{C}$ and, in smokers, vitamin $\mathrm{E}$ was associated with a reduced risk of stroke.

see page 1273

\section{Botulinum toxin A for management of drooling}

Lipp et al. compared three different dosages of botulinum toxin A (BTX-A) vs placebo in 32 patients with sialorrhea. A significant reduction of drooling was achieved with 75 MU BTX-A injected into the parotid gland of each side.

see page 1279

\section{Intracranial hypertension after epidural blood patch}

Epidural blood patch is a generally safe and effective therapy for post-lumbar puncture headache. Cestari and Rizzo report a case of intracranial hypertension after an epidural blood patch.

see page 1303

\section{CME TAKE ADVANTAGE OF NEUROLOGY CME ONLINE}

The online version of Neurology includes a continuing medical education (CME) component that is only available to subscribers. The AAN designates this educational activity for up to 72 hours in Category 1 towards the American Medical Association (AMA) Physician's Recognition Award (3 hours per completed online issue).

Using this system, subscribers can:

- Take the quizzes online

- Receive instant feedback on their selected answers

- Submit completed issue quizzes for CME credit, and receive confirmation of credit immediately via email

- Review all the credits they've earned via Neurology Online's individualized CME Summary Report 


\title{
Neurology
}

\author{
November 11 Highlights \\ Neurology 2003;61;1166-1167 \\ DOI 10.1212/WNL.61.9.1166
}

This information is current as of November 10, 2003

\section{Updated Information \&}

Services

Permissions \& Licensing

Reprints including high resolution figures, can be found at: http://n.neurology.org/content/61/9/1166.full

Information about reproducing this article in parts (figures,tables) or in its entirety can be found online at:

http://www.neurology.org/about/about_the_journal\#permissions

Information about ordering reprints can be found online:

http://n.neurology.org/subscribers/advertise

Neurology ${ }^{\circledR}$ is the official journal of the American Academy of Neurology. Published continuously since 1951, it is now a weekly with 48 issues per year. Copyright . All rights reserved. Print ISSN: 0028-3878. Online ISSN: 1526-632X.

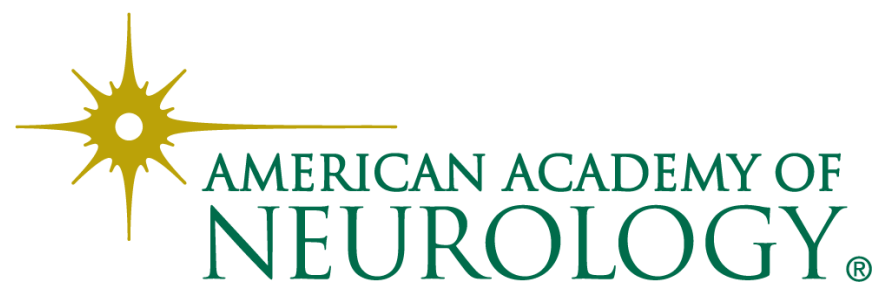

